\title{
PRÁtica de SD dURANTE O EnSINO ReMoto: MARCAS DA VIOLÊNCIA CONTRA A MULHER EM CONTOS DE MARINA COLASANTI
}

\author{
SD PRACTICE DURING REMOTE EDUCATION: MARKS OF VIOLENCE AGAINST WOMAN IN \\ TALES BY MARINA COLASANTI
}

PRÁCTICA DE DS DURANTE LA EDUCACIÓN A DISTANCIA: MARCAS DE VIOLENCIA CONTRA LA MUJER EN LOS CUENTOS DE MARINA COLASANTI

\author{
Márcia de Souza \\ Damasceno \\ (iD) 9 \\ Mestranda em Ensino \\ (IFMT/UNIC) \\ Professora no Centro Municipal de \\ Educação Básica Helena Esteves \\ Discente da Pós-Graduação - \\ Mestrado em Ensino \\ (IFMT/UNIC) \\ marcinhadama@live.com
}

\section{Claudia Lucia Landgraf Valério \\ (iD) 9}

Doutora em Língua Portuguesa (PUC- SP)

Professora no Instituto Federal de Mato Grosso (IFMT)

Docente na Pós-Graduação -

Mestrado em Ensino

(IFMT/UNIC)

claudia.valerio@cba.ifmt.edu.br

\section{Epaminondas Matos de}

Magalhães

\section{iD 9}

Doutor em Letras - Teoria da Literatura (PUC/RS)

Professor no Instituto Federal de Mato Grosso (IFMT)

Docente na Pós-Graduação de Mestrado em Ensino (IFMT/UNIC) e do Programa de Pós-Graduação em Estudos Literários (PPGEL-UNEMAT) epaminondas.magalhaes@plc.ifmt. edu.br

\begin{abstract}
Resumo
Este artigo tem como objetivo apresentar o trabalho realizado por meio de sequência didática (SD) sobre a violência contra a mulher nos contos de Marina Colasanti. A relevância do tema deve-se ao aumento de casos de violência doméstica no Brasil, em meio à Pandemia do Covid-19. O estudo resultou das reflexões acerca de um trabalho desenvolvido com a finalidade de possibilitar aprendizagens significativas que promovam transformações sociais, dentre elas a igualdade de gênero para, assim, reduzirmos a violência contra as mulheres. Nessa acepção, o aporte teórico foi construído com as contribuições de autores que corroboram com as discussões aqui expostas, ancorados na proposta de uma SD, dispositivo metodológico para apropriação de práticas de linguagem configuradas em gêneros de textos, realizada com estudantes do Ensino Médio, na cidade de Barra do Garças-MT, em meio ao contexto de pandemia. Os resultados mostraram que houve uma mudança de percepção dos estudantes quanto ao gênero conto e a conscientização do papel da mulher na sociedade.
\end{abstract}

Palavras-chave: Ensino remoto. Leitura e escrita. Mulher. Marina Colasanti.

Recebido em: 24 de maio de 2021. Aprovado em: 28 de junho de 2021.

Como citar esse artigo (ABNT):

DAMASCENO, Márcia de Souza; VALÉRIO, Claudia Lucia Landgraf; MAGALHÃES, Epaminondas Matos de. Prática de SD durante o Ensino Remoto: marcas da violência contra a mulher em contos de Marina Colasanti. Revista Prática Docente, v. 6, n. 2, e047, 2021. http://doi.org/10.23926/RPD.2021.v6.n2.e047.id1188 


\section{Abstract}

This article aims to present the work carried out by means of a didactic sequence (SD) on violence against women, presenting tales by Marina Colasanti. The relevance of the theme was due to the increase in cases of domestic violence in Brazil in the midst of the Covid-19 Pandemic. The study resulted from reflections on a work developed with the purpose of enabling meaningful learning that promotes social transformations, including gender equality, so that we can reduce violence against women. In this sense, the theoretical contribution was built with the contributions of authors that corroborate the discussion exposed here, anchored in the proposal of an SD, methodological device for the appropriation of language practices configured in text genres, carried out with high school students, in the city of Barra do Garças - MT, in the context of a pandemic context. The results showed that there was a change in the students' perception of the short story and the awareness of the role of women in society.

Keywords: Remote teaching. Reading and writing. Woman. Marina Colasanti.

\section{Resumen}

Este artículo tiene como objetivo presentar el trabajo realizado mediante una secuencia didáctica (SD) sobre la violencia contra las mujeres, presentando relatos de Marina Colasanti. La relevancia del tema se debió al aumento de casos de violencia doméstica en Brasil en medio de la Pandemia Covid-19. El estudio es el resultado de reflexiones sobre un trabajo desarrollado con el propósito de posibilitar un aprendizaje significativo que promueva transformaciones sociales, incluida la igualdad de género, para que podamos reducir la violencia contra las mujeres. En este sentido, el aporte teórico se construyó con los aportes de los autores que corroboran la discusión aquí expuesta, anclada en la propuesta de un DS, dispositivo metodológico para la apropiación de prácticas lingüísticas configuradas en géneros textuales, realizado con estudiantes de secundaria, en la ciudad de Barra do Garças - MT, en el contexto de una contexto pandémico. Los resultados mostraron que hubo un cambio en la percepción de los estudiantes sobre el cuento y la conciencia del papel de la mujer en la sociedad.

Palabras clave: Enseñanza remota. Leyendo y escribiendo. Mujer. Marina Colasanti. 


\section{INTRODUÇÃO}

A chegada da Covid-19 $19^{1}$, no Brasil, desencadeou diversas medidas de controle e prevenção da doença, por parte das autoridades sanitárias, em diferentes esferas administrativas (federal, estadual e municipal). Essas medidas se diferenciam de uma região para outra no país; entretanto, a medida mais difundida tem sido a prática do distanciamento social. De acordo com Fornari et al. (2021), logo após iniciar o confinamento, aumentaram os índices de violência, pois, o espaço doméstico constitui lócus privilegiado de ocorrência da violência contra a mulher.

Nesse contexto, o isolamento levou ao aumento exponencial do convívio, ampliando as possibilidades de intensificar os desgastes familiares, inclusive da mulher com o agressor. Situações como a instabilidade econômica e o desemprego também reforçaram a dependência econômica das mulheres, passando a ameaçar mais o status do homem culturalmente construído como provedor, tendo como consequência a violência intrafamiliar como mecanismo de reafirmação do poder masculino. Outrossim, pelos dados da (FBSP, 2020), as denúncias ao Ligue 180 - número de telefone para reportar a violência contra as mulheres - aumentaram 17,9\% em março e 37,6\% em abril de 2020, e os feminicídios cresceram 22\% em 12 estados. Essa violência se estende às crianças e adolescentes em idade escolar, que necessitavam da escola (espaço físico) como um abrigo, um porto seguro.

Todavia, diante do risco de contágio representado pelas aglomerações, comum na educação presencial, foi determinado como medida de enfrentamento, o fechamento das unidades educacionais, passando o ensino a ser ministrado na modalidade não presencial, desde março de 2020. O termo "remoto" alude a distante no espaço e se refere a um distanciamento geográfico. O ensino é considerado remoto já que os professores e estudantes estão impedidos, por portarias, de frequentarem instituições educacionais para evitarem a disseminação do vírus e é emergencial por se tratar de uma solução.

Assim, para seguirmos com ensino, utilizamos as diversas tecnologias de informação e comunicação no trabalho docente. Para Galindo (2012), o crescimento da utilização de Tecnologias da Informação e Comunicação (TIC) na área da educação, como possibilidade para o processo de práticas pedagógicas, deve-se ao fato de que o smartphone passou a ser uma extensão do corpo, tanto do professor quanto do estudante, para realizações de diversas

\footnotetext{
${ }^{1}$ A COVID-19 é uma doença causada pelo coronavírus SARS-CoV-2, que apresenta um quadro clínico que varia de infecções assintomáticas a quadros respiratórios graves. (MINISTÉRIO DA SAÚDE (Brasil), [2020]). 
atividades do cotidiano, dentre elas, comunicação, interação, informação, produção de conteúdo e ferramenta de trabalho.

Nesse contexto, o estudo dos gêneros discursivos/textuais tem ocupado uma posição imprescindível, já que "[...] todas as esferas da atividade humana, por mais variadas que sejam, estão sempre relacionadas com a utilização da língua" (BAKHTIN, 2000, p. 279). Assim, é a língua em funcionamento que deve ser levada em consideração. Nesse sentido, os contos de Marina Colasanti apresentam uma temática social que faz parte do contexto dos estudantes, possibilitando maior compreensão do gênero.

De acordo com Bakhtin (2000), o enunciado refere-se à unidade concreta e real da comunicação discursiva. Cada enunciado é um novo e único acontecimento, mas pode manter relações dialógicas com outros enunciados, surgindo como resposta a outros ou mantendo relação com enunciados que o seguem. Ademais, não é composto tão somente de parte verbal, mas também de parte social, como partes intrínsecas, não externas.

Em se tratando de gêneros discursivos, o literário tem estado mais presente e, na maioria das vezes, é disponibilizado para o estudante lê-lo em horários extraclasses, por ser uma leitura prazerosa. Sabemos que o leitor busca atribuir significado a tudo o que lê, conforme os conhecimentos de mundo que possui e a leitura acontece a partir de conhecimentos anteriores. Logo, cabe ao educando atribuir significados a suas leituras. Vale destacar que as práticas sociais da leitura acontecem de várias maneiras e a partir de diferentes necessidades, dentre elas, as questões sociais.

De maneira a contribuir com práticas que admitam uma maior inclusão estudantil nas atividades de leitura e escrita, este trabalho apresenta uma sequência didática realizada com turmas do Ensino Médio, da Escola Estadual Deputado Norberto Schwantes, localizada em um bairro periférico do munícipio de Barra do Garças-MT, compreendendo o gênero conto, assim como a temática trazida pelos contos. Portanto, devido ao tom discursivo que caracteriza o referido gênero, a interação autor-texto-leitor vai se estabelecendo e dirigindo o estudante a refletir criticamente sobre uma heterogeneidade de fatos, sobretudo as que se arrolam ao mundo que o cerca. Nesse sentido, para Lajolo (1986), o texto deve ser usado para proporcionar ao estudante uma reflexão sobre como se produz sentidos por meio da língua, ou seja, por mediação de textos.

Adotamos a concepção interacional de língua, de sujeito e de texto. Ao assumirmos esta concepção, a compreendemos como uma atividade interativa, complexa na produção de 
sentidos, que se realiza com base nos elementos linguísticos presentes na superfície textual e na sua forma de organização.

Nas palavras de Bakhtin, o texto constitui a realidade imediata para que se possa estudar o homem social e a sua linguagem, já que sua constituição bem como sua linguagem é mediada pelo texto; é através do texto que o homem exprime suas ideias e sentimentos. (BAKHTIN, 2000). De tal modo que a consciência da textualidade traz à baila a importância do uso da língua em textos orais e escritos, como defendido nos Parâmetros Curriculares Nacionais (PCN's), regulamento pela Base Nacional Comum Curricular (BNCC) e o Documento de Referência Curricular para Mato Grosso (DRC-MT): o ensino contextualizado com o texto e não baseado no texto.

Partindo dessas considerações, as seções deste trabalho discutem o ensino remoto, os contos de Marina Colasanti enquanto gênero sócio-discursivo e a sequência didática executada neste momento pandêmico mediada pelas Tecnologia da Informação e Comunicação (TIC). Por fim, trazemos os resultados do trabalho e deixamos uma reflexão acerca da importância de trabalhar gênero discursivo literário para contextualizar a Violência contra a mulher.

\section{O ENSINO REMOTO E SUAS IMPLICAÇÕES}

De forma abrupta, após deliberada como medida o isolamento social, o Conselho Nacional de Educação (CNE), por meio do Parecer No 5/2020, estabeleceu que as atividades pedagógicas não presenciais seriam computadas para fins de cumprimento da carga horária mínima anual. Tornando responsabilidade de cada Secretaria de Estado organizar suas ações para o atendimento educacional. Desta feita, as Secretarias de Estado deixaram a cargo das Secretarias Municipais decidirem suas organizações, de acordo com a realidade de cada município, assim como a realidade de cada unidade escolar.

O órgão colegiado salientou que essas atividades poderiam ser executadas por meios digitais (vídeo-aulas, conteúdos organizados em plataformas virtuais de ensino e aprendizagem, redes sociais, correio eletrônico, blogs, entre outros); por meio de programas de televisão ou rádio; pela adoção de material didático impresso com orientações pedagógicas distribuído aos estudantes e/ou seus pais ou responsáveis; e pela orientação de leituras, projetos, pesquisas, atividades e exercícios indicados nos materiais didáticos (BRASIL, 2020b).

A partir do parecer do CNE, o Estado de Mato Grosso, elaborou orientações educacionais por meio do Decreto Executivo (MT) n ${ }^{\circ}$ 406, de 16 de março de 2020, para a realização de aulas e atividades pedagógicas na modalidade não presencial. Logo, adotaram 
estratégias como o uso de plataformas on-line, vídeo-aulas gravadas e compartilhamento de materiais digitais. (CIEB, 2020). Todavia, percebemos que algumas medidas somente trouxeram ao cenário as diversas desigualdades sociais, visto que muitas comunidades não possuem acesso nem domínio das ferramentas digitais.

Denominaram a modalidade não presencial como Ensino Remoto Emergencial (ERE), pelo termo "remoto" aludir a distante no espaço e se referir a um distanciamento geográfico. $\mathrm{O}$ ensino é considerado remoto, uma vez que os professores e estudantes estão impedidos, por portarias, de frequentarem instituições educacionais para evitarem a disseminação do vírus. Além disso, é emergencial por se tratar de uma solução.

Em relação a reorganização escolar, o CNE considerou-a como um ciclo emergencial que visa à mitigação dos impactos da pandemia na educação, em razão da longa duração da suspensão das atividades educacionais de forma presencial nas escolas. Contudo, o órgão colegiado evidenciou que, independente da estratégia adotada, as redes de ensino devem: i) ter como finalidade o atendimento dos direitos e objetivos de aprendizagem previstos para cada série/ano; ii) assegurar e manter o padrão de qualidade previsto em leis (Lei de Diretrizes e Bases da Educação e Constituição Federal); iii) cumprir a carga horária mínima prevista na LDB; iv) evitar retrocesso de aprendizagem por parte dos estudantes e a perda do vínculo com a escola; v) observar a realidade e os limites de acesso dos estabelecimentos de ensino e dos estudantes às diversas tecnologias, sendo necessário considerar propostas inclusivas e que não reforcem ou aumentem a desigualdade de oportunidades educacionais e; vi) garantir uma avaliação equilibrada dos estudantes, assegurando as mesmas oportunidades a todos e evitando o aumento da reprovação e do abandono escolar (BRASIL, 2020b).

Nesse escopo, existe por parte das unidades escolares o compromisso de cumprir o que o CNE pontuou. Contudo, para isso, não basta apenas a mobilização dos profissionais da educação, pois estes não têm medido esforços para levar ao estudante a melhor proposta possível, o melhor ensino com as condições precárias que algumas unidades possuem. Há que considerar, também, que muitas famílias não conseguem realizar o acompanhamento necessário com o estudante que tem apenas a apostila em mãos.

A escola lócus do trabalho, Norberto Schwantes, que atende aos anos finais do ensino fundamental e ensino médio, possibilita o ERE por meio de apostilas elaboradas mensalmente e retiradas na unidade escolar pelos responsáveis ou estudantes, que não possuem acesso às ferramentas digitais. Por outro lado, atendendo a demanda de quem possui acesso à internet, 
são fornecidas apostilas em formatos digitais e momentos síncronos utilizando aplicativos nativos nos aparelhos celulares e de fácil acesso e manuseio tanto dos estudantes quanto dos professores.

Para o Ministério da Educação (MEC), faz-se importante que, neste período de afastamento presencial, as escolas orientem alunos e famílias a elaborarem um planejamento de estudos, com o acompanhamento do cumprimento das atividades pedagógicas não presenciais por mediadores familiares (BRASIL, 2020b, p. 9). É imprescindível o acompanhamento e mediação de um adulto para orientação dos estudantes dos anos iniciais do ensino fundamental, em razão das dificuldades desses estudantes para acompanharem e realizarem as atividades on-line ou apostilas. Devido maior autonomia os estudantes dos anos finais do ensino fundamental e do ensino médio, estes necessitam apenas de orientação, de um mediador.

Faz-se necessário clarear os conceitos de mediador/supervisor e professor. O processo educativo, essencialmente pedagógico, é função do professor. O mediador apenas acompanha e orienta o estudante na organização de sua rotina diária de estudos e não substitui a atividade profissional do professor. (BRASIL, 2020b).

Sabemos que o ensino remoto foi resultado de uma emergência, e por mais que tenha ocorrido um esforço de planejamento por parte dos sistemas de ensino, as debilidades técnicas e estruturais condicionam um cenário que pode ser definido como: "o que temos pra hoje" (SANTOS, 2020). Ainda nesta perspectiva, a autora confirma que essa situação emergencial tem muitas limitações. Pensando nessas limitações e no atual cenário em que muitos estudantes estão vivenciando a violência doméstica, fez-se necessário a escolha da temática para a realização das atividades, para que se sentissem acolhidos e instruídos.

\section{Os CONTOS DE MARINa COLASANTI E O GÊNERO DISCURSIVO}

Marina Colasanti é uma escritora contemporânea, que trouxe uma atuação relevante, principalmente como jornalista, no sentido de aclarar e dar maior consciência às mulheres brasileiras quanto à sua condição. Casada com o escritor e crítico Affonso Romano de Sant'Anna, a autora nasceu na Etiópia em 1937 e vive no Brasil desde os onze anos.

Quanto a sua produção literária, Marina escreveu mais de quarenta obras, incluindo contos, crônicas, poesias, ensaios e histórias infantis. Sua atuação feminista nas décadas de 70/80 foi imprescindível na tentativa de modernizar a cultura e os costumes machistas e 
patriarcais do país. Neste período, atuou tanto na imprensa (jornais e revistas) como na publicação de livros que publicou sobre a temática.

A autora, por ser feminista, acredita que a história das mulheres na sociedade é muito relevante, reconhece as limitações que são impostas ao sexo feminino e procura refletir isso em suas obras. Dentre toda a riqueza de sua obra, escolhemos trabalhar os contos "Para que ninguém a quisesse" e “, Porém igualmente", da obra "Um espinhos de Marfim e outras histórias", publicada em 1999.

Porque os homens olhavam demais para a sua mulher, mandou que descesse a bainha dos vestidos e parasse de se pintar. Apesar disso, sua beleza chamava a atenção, e ele foi obrigado a exigir que eliminasse os decotes, jogasse fora os sapatos de saltos altos. Dos armários tirou as roupas de seda, da gaveta tirou todas as joias. E vendo que, ainda assim, um ou outro olhar viril se acendia à passagem dela, pegou a tesoura $\mathrm{e}$ tosquiou-lhe os longos cabelos. Agora podia viver descansado. Ninguém a olhava duas vezes, homem nenhum se interessava por ela. Esquiva como um gato, não mais atravessava praças. E evitava sair. Tão esquiva se fez, que ele foi deixando de ocuparse dela, permitindo que fluísse em silêncio pelos cômodos, mimetizada com os móveis e as sombras. Uma fina saudade, porém, começou a alinhavar-se em seus dias. Não saudade da mulher. Mas do desejo inflamado que tivera por ela. Então lhe trouxe um batom. No outro dia um corte de seda. À noite tirou do bolso uma rosa de cetim para enfeitar-lhe o que restava dos cabelos. Mas ela tinha desaprendido a gostar dessas coisas, nem pensava mais em lhe agradar. Largou o tecido em uma gaveta, esqueceu o batom. E continuou andando pela casa de vestido de chita, enquanto a rosa desbotava sobre a cômoda (COLASANTI, 1999, p. 88-9).

No conto, "Para que ninguém a quisesse", a autora retrata uma mulher que sofre violência psicológica, a qual é totalmente descaracterizada pelo marido, devido ao ciúme doentio dele, deixando transparecer a submissão feminina e a perda da identidade. Por outro lado, retrata uma sociedade machista e patriarcal, que culpa a mulher por despertar desejo em outros homens, não deixando claro durante o texto se ela realmente o fazia. A descaracterização foi tão forte que, ao final, nem mesmo o marido se interessava mais por ela, não mais sentia desejo pela esposa. Já no conto, "Porém igualmente", a autora retrata outros tipos de violência, a doméstica e a física, que culmina na morte da protagonista, uma mulher silenciada pela agressão, invisível a sociedade e a família.

É uma santa. Diziam os vizinhos. E D. Eulália apanhando.

É um anjo. Diziam os parentes. E D. Eulália sangrando.

Porém igualmente se surpreenderam na noite em que, mais bêbado que de costume, o marido, depois de surrá-la, jogou-a pela janela, e D. Eulália rompeu em asas o vôo de sua trajetória (COLASANTI, 1999, p. 44)

D. Eulália é o retrato de várias mulheres brasileiras. Em poucas linhas, a autora trabalha a agressão física, que culmina em feminicídio e o leitor se depara com uma situação de abuso 
que várias vezes é invisível à sociedade, e que só, e infelizmente, ganha visibilidade após morte da "mulher", da esposa.

De acordo com Torres (2008), os contos de Marina:

$$
\begin{aligned}
& \text {...refletem uma ideologia crítica acerca dos valores sociais, visando a mudanças de } \\
& \text { atitudes na cultura. Ela realiza o resgate dos mitos que aparecem, basicamente, como } \\
& \text { suporte para a valorização de um discurso do corpo, de uma voz feminina calada por } \\
& \text { vários anos de repressão, sugerindo a manifestação dos desejos de individuação e } \\
& \text { ascensão (TORRES, 2008, p. 06). }
\end{aligned}
$$

Dada a importância social da obra e da linguagem, os contos escolhidos corroboram com a abordagem dos documentos oficiais referentes ao ensino de língua materna, tanto os Parâmetros Curriculares Nacionais (PCN), quanto a Base Nacional Comum Curricular (BNCC) e o Documento Referencial de Mato Grosso (DRC-MT), os quais trazem eu seu texto a importância da linguagem como "uma forma de ação interindividual orientada para uma finalidade específica; um processo de interlocução que se realiza nas práticas sociais existentes numa sociedade, nos distintos momentos de sua história" (BRASIL, 1998, p. 20).

Ademais, a escolha do gênero conto se deu pela sua celeridade (desenrolar da ação em apenas um episódio), pelo envolvimento de poucas personagens, pelo espaço físico diminuto (lugar único) e pelo tempo marcado por um período muito curto, o que agiliza a análise em um contexto real de aula, tornando-se mais atraente ao estudante, possibilitando maior espaço para a oralidade e para as discussões. Quanto ao gênero, podemos dizer que é discursivo e a sua composição estrutural apresenta a introdução, o desenvolvimento, o clímax e o desfecho.

Uma vez que o conceito de gênero se reporta diretamente ao funcionamento de textos em eventos comunicativos reais e concretos, construídos em espaços sociais em que as pessoas agem, interagem e assumem papéis comunicativos e posições sociais específicas, partimos para uma abordagem do ponto de vista discursivo. Acreditamos que o conto se constitui, segundo uma visão bakhtiniana, em uma atividade de leitura e de escrita concreta e histórica; com propriedades relativamente estáveis, ligadas a uma situação típica da comunicação social; e com traços temáticos, estilísticos e composicionais concernentes a enunciados individuais e, dessa forma, ligados à atividade humana.

Bakhtin (2000) assegura que os gêneros discursivos estão presentes em todo o tipo de atividade humana permeada pela linguagem, pois servem para guiar e organizar nossas ações sociais. Há, contudo, algumas distinções entre a forma como utilizamos a linguagem nas diferentes situações em que nos encontramos, o que reflete, diretamente, na caracterização do 
autor em relação aos gêneros discursivos. Nesse sentido, o conto com a temática da mulher tornou-se significativo aos estudantes, neste momento de isolamento.

Abarcamos ao mesmo tempo a oralização de textos, presente no texto da BNCC como “...situação oral com ou sem contato face a face...”, para o que consideramos uma situação socialmente significativa, interagimos envolvendo a temática e outras dimensões linguísticas do trabalho com texto oralizado. (BNCC, 2017. p. 75).

\section{CONSTRUÇÃo E EXECUÇÃo da SEQuÊnCIA DidÁtica}

A expressão sequência didática está presente no cotidiano docente, pois esta prática é pautada em um gênero, ou seja, a elaboração de uma Sequência Didática (SD) não acontece sem o trabalho com um gênero textual (seja ele escrito ou oral). Aportados na teoria de Dolz e Schneuwly (2004), ressaltamos que o "interacionismo social" ocorre por meio da relação do indivíduo com o contexto e do uso que ele faz da linguagem. Nesse viés, é preciso desenvolver situações de comunicação em que o estudante demonstre autonomia enquanto leitor e cidadão, sendo o professor o mediador entre o aprendiz e o texto. Para os autores uma SD necessita de:

[...] módulos de ensino, organizados conjuntamente para melhorar uma determinada prática de linguagem. As sequências didáticas instauram uma primeira relação entre um projeto de apropriação de uma prática de linguagem e os instrumentos que facilitam essa apropriação. Desse ponto de vista, elas buscam confrontar os estudantes com práticas de linguagem historicamente construídas, os gêneros textuais, para lhes dar a possibilidade de reconstruí-las e delas se apropriarem. Essa reconstrução realizase graças à interação de três fatores: as especificidades das práticas de linguagem que são objeto de aprendizagem, as capacidades de linguagem dos aprendizes e as estratégias de ensino propostas pela sequência didática (DOLZ e SCHNEUWLY 2004, p. 43).

Uma SD é um conjunto de atividades organizadas em torno de gênero oral ou escrito, de maneira sistemática. Portanto, tem a função de possibilitar aos estudantes o acesso a novas, ou pouco dominadas, práticas de linguagem. O desempenho dos aprendizes precisa ser objeto de análise, adaptando-se as sequências às necessidades dos estudantes para que sejam capazes de mobilizar o conteúdo temático, em razão do gênero, e organizá-lo de maneira adequada, em função das especificidades de cada gênero.

Outrossim, as atividades a serem utilizadas em uma sequência didática devem ser selecionadas, adaptadas e transformadas de acordo com as necessidades dos estudantes, do momento em que são escolhidas para serem trabalhadas. Por isso, a produção inicial da SD merece um olhar atento do professor para que essas adaptações sejam possíveis de serem realizadas, pois é nesse momento da SD que o estudante revela as representações que têm do 
gênero em estudo e possibilita ao professor observar em que ponto deve intervir e como executar essa intervenção.

Dolz e Schneuwly (2004) apresentam um modelo comum para representar a SD. Nesse modelo, aparecem quatro etapas para o processo de aprendizagem de um dado gênero, sendo a apresentação inicial, a produção inicial, os módulos e a produção final. Destacamos que a sequência aqui proposta foi planejada para ser executada com estudantes na faixa etária dos 15 aos 18 anos, na modalidade remota de forma online, segundo a estrutura apresentada acima, para ser desenvolvida em três módulos com cerca de seis aulas de uma hora cada uma, totalizando, aproximadamente, vinte horas, sendo consideradas atividades complementares. Todos os momentos da SD foram mediados ora Google Meet, ora WhatsApp e as atividades realizadas via Google Formulários.

\section{1. $1^{\circ}$ Módulo - APRESENTAÇão da SituaÇão E ProduÇÃo INICIAL}

O projeto e situação comunicativa da sequência didática para estudo do gênero discursivo conto foi apresentado aos estudantes para que compreendessem a importância dos trabalhos que desenvolveríamos durante as etapas da sequência.

A finalidade foi apresentar aos estudantes um projeto de comunicação que seria realizado realmente na produção final. Para ilustrar a temática, iniciamos com algumas imagens e vídeos retratando a violência contra a mulher. Em seguida, debatemos sobre o tema e questionamos sobre qual gênero trata dessa temática e trabalhamos com a narração. Visto que, sabemos que a apresentação da situação prepara os estudantes para a produção inicial, que é considerada uma primeira tentativa de realização do gênero que será, em seguida, trabalhado em módulos, realizamos a leitura dos contos de Marina.

No período da produção inicial, realizada após conhecerem o gênero discursivo, os estudantes produziram um conto de livre temática, utilizando o que conheciam sobre a curta narrativa, alguns produziram utilizando a plataforma digital Google Documentos, enquanto outros fizeram no caderno.

\section{2. $2^{\circ}$ Módulo - ReVisitando o gÊNERo ConTo}

\subsubsection{OfiCina 1 - A ORganizaÇÃo do MATERIAl A SER UTILIZAdo Na SEQUÊNCIA DIDÁTICA}

Os estudantes fizeram um levantamento biográfico e literário de Marina Colasanti e uma pesquisa sobre os índices de violência contra a mulher no país. Para isso, utilizaram os 
aplicativos de busca e pesquisa on-line. Após as pesquisas, os estudantes decidiram compartilhar os resultados com os colegas de maneira síncrona e também assíncrona.

\subsubsection{OFICINA 2 - EXERCÍCIOS EM GRUPO E INDIVIDUAIS}

Sugerimos atividades diversificadas, em torno das categorias de análise do gênero, dando destaque às características que eles já dominavam e as que eles precisavam aprender sobre os contos e desmitificar o gênero. Nesta fase, os estudantes realizaram diferentes tarefas de compreensão e interpretação textual com o objetivo de apropriação das características do gênero estudado, a fim de verificar como se organiza a infraestrutura textual e as unidades linguístico-discursivas dos mecanismos de textualização e dos mecanismos enunciativos dos contos.

De acordo com Dolz e Schneuwly (2004), todo gênero se define por três dimensões essenciais: 1) Os conteúdos que são dizíveis através dele; 2) A estrutura particular dos textos pertencentes ao gênero e 3) As configurações específicas das unidades de linguagem. A linguagem utilizada em um conto será influenciada pelo público destinado. Assim, os contos de Marina ganharam repercussão e visibilidade pela linguagem simples e brevidade dos textos.

Para os autores, as atividades de observação e análise de textos possibilitam a comparação da estrutura organizacional dos exemplares analisados, destacando aspectos que se repetem em todos e que, consequentemente, caracterizam um conto, ou seja, constituem-se como suas regularidades. Na sequência, os estudantes fizeram tarefas simplificadas de leitura e compreensão, visando a apropriação de conhecimentos textuais e linguísticos.

\section{3. $3^{\circ}$ MÓDULO - REFACÇÃo DA PRODUÇÃo INICIAL}

Após adquirem progressivamente conhecimentos sobre o gênero, os estudantes empregaram, na prática, os conceitos desenvolvidos nas etapas anteriores, revisitaram seus textos para verificarem se estavam escritos com a estrutura composicional do gênero, além de revisarem a parte gramatical, finalizando, assim, as produções.

\section{4. $4^{\circ}$ Módulo - ProduÇão Final}

A produção final foi realizada individualmente, seguindo a proposta de utilizar o gênero conto para trabalhar a violência doméstica. Após refletirem sobre o tema que aflige a sociedade neste contexto pandêmico, os estudantes realizaram a escrita, a revisão e a socialização dos textos. 
Todas as contribuições fizeram parte do processo de avaliação da sequência didática desenvolvida, porém precisamos salientar que a avaliação foi processual e consideramos o desenvolvimento dos estudantes desde a primeira produção até a produção final.

\title{
5 Resultados E Discussões
}

O trabalho com a SD foi realizado no mês de fevereiro de 2021 e surpreendeu devido ao engajamento dos estudantes em compreender o gênero e discutir mais sobre a temática que envolve a sociedade em seus mais distintos contextos. A violência contra a mulher não escolhe cor, raça e classe social. Nesse sentido, o trabalho possibilitou aos estudantes uma outra visão em relação ao tema, quando analisaram D. Eulália, personagem do conto, todos fizeram a mesma leitura, uma mulher negra, magra e pobre, que se confirma nesta leitura enviada, via WhatsApp, por uma estudante.

Figura 1 - Análise física da personagem D. Eulália

\begin{abstract}
Eu acho que ele deveria ser uma mulher pequena e magra, talvez abaixo do peso, já que na história diz que o marido dela a jogou pela janela mesmo estando bêbado, ela deveria ser cheia de hematomas pelo corpo principalmente nos braços, já que quando vc quer se defender de algo vc usa os braços, ela deveria ser fraca já que ela não conseguiu segurar nada ou até mesmo bater no marido para que ele a soltasse. Cabelos pretos por que acho mais comum e morena ou negra e olhos castanhos escuros.

$19: 12$
\end{abstract}

Fonte: Dados da Pesquisa (2021).

Percebemos que a estudante faz a leitura utilizando elementos do texto, porém o que fica claro, dentro da leitura, é que no país a violência ataca mais pessoas negras, pois existe um preconceito velado que se faz presente todos os dias nos noticiários, quando apresentam somente a violência contra a mulher negra e pobre. Todavia, quando solicitado aos estudantes que descrevessem a personagem do conto "Para que Ninguém a quisesse", a maioria das respostas obtidas foi outra.

Figura 2 - Análise física da personagem "Para que ninguém a quisesse"

Uma linda mulher com um corpão, que possui um olhar brilhante, com cabelo sedoso e macio, loira e cheia de charme, que chamava atenção de todo mundo por onde passava.

Fonte: Dados da Pesquisa (2021).

De acordo com a pesquisadora Alba Zaluar (1994), essa estigmatização faz, inclusive, com que o negro seja sinônimo de violento e pobre e a mulher de vítima e sofredora. Ou do 
outro lado, sendo, estatisticamente mais vitimizado pela violência, mais acometido pelo desemprego e pela falta de representatividade. Diante de todos os aspectos históricos, sociais, culturais, econômicos, políticos que envolvem a questão do subjugo racial no Brasil, pode-se dizer que para abolir o preconceito é necessário a educação, sendo importante que estes temas povoem as salas de aula.

Neste contexto pandêmico, escolhemos o conto por ser uma narrativa de fácil compreensão, trabalhamos de forma assíncrona, via apostilas, e também a partir de aulas síncronas via Google Meet, com tempo reduzido. A escolha do gênero possibilitou espaço para a discussão da temática, para a interação com os estudantes, que se manifestaram ora no chat ora abrindo os microfones para debatermos o estudo, especificidade do gênero e as questões de violência feminina.

Quanto as produções textuais, a que mais chamou atenção foi uma releitura de "Porém Igualmente", que faz uma denúncia sobre a violência infantil. Na ocasião, o estudante utilizou a escrita para socializar com o grupo que não só as mulheres, mas também crianças e adolescentes sofrem de forma velada.

É um gênio. Diziam os vizinhos. E D. Pedro apanhando.

É um anjo. Diziam os parentes. E D. Pedro sangrando após sofrer abuso sexual.

Porém igualmente se surpreenderam na noite em que, mais bêbado que de costume, o padrasto, depois de surrá-lo e abusá-lo, jogou-o pela janela, e D. Pedro rompeu em asas o voo de sua trajetória (G.S.S $-1^{\circ}$ ano do Ensino Médio)

Por fim, observamos que o trabalho de leitura e escrita de forma eficiente deve ser visto como uma prioridade, assim como utilizar um gênero discursivo literário para trabalhar temas como a Violência. Ademais, a escrita é essencial para os estudantes expressarem sentimentos, ideias, reflexões, fomentando uma melhor interação social com o mundo.

\section{CONSIDERAÇÕES FINAIS}

Atividades que instigam os estudantes possibilitando a reflexão sobre o que assistem e escutam em seu contexto são fundamentais para que aconteçam transformações na sociedade, a fim de promover a tolerância e o respeito, na luta contra o preconceito e a violência. Percebemos que a figura do professor interventor deve compreender as nuances deste novo panorama tanto no campo social quanto tecnológico. Para tanto, é preciso entender que o estudante também é um agente ativo no processo educacional e encontra-se inserido em um contexto muitas vezes ignorado. Logo, devemos incluir os estudantes, respeitar sua história, seu 
lugar de fala e observar o processo de aquisição de conteúdo, bem como acontece a aprendizagem.

Os estudantes precisam, portanto, criar uma identidade, conhecer a comunidade a que pertencem e compreender que toda fala carrega uma carga ideológica. Com o auxílio do professor, eles compreenderão e regularão suas aprendizagens, por intermédio da análise de seus processos cognitivos e metacognitivos, sendo necessário conduzir processos de autoavaliação para serem autores de sua própria aprendizagem, demonstrando iniciativa e autonomia.

Ademais, compreendemos que a utilização das tecnologias na educação (TIC) assinala para que não sejam meras ferramentas do ensinar, mas aliadas na promoção de condições de aprendizagem. Para Valente (1995), isto significa que o professor tem que abandonar o papel de transmissor de informação e se transformar no criador de ambientes de aprendizagem, no facilitador do processo de desenvolvimento intelectual do estudante.

A incorporação da SD e a utilização da temática trazida nos contos de Marina Colasanti permitiram observarmos melhor a dinâmica entre conteúdo, engajamento e prática através do processo de construção do conhecimento, em meio às diferentes metodologias de ensino.

Destarte, finalizamos este trabalho ressaltando o fato de que, após a análise da SD aplicada aos estudantes, os resultados mostraram que eles foram capazes de significar conceitos, tomar conhecimento de um conteúdo pela leitura, conhecer as funções sociais da língua e produzir contos com temas relevantes, utilizando os conhecimentos linguísticos. Verificamos, também, a relevância em se abordar a violência contra a mulher dentro do ambiente escolar, visando, principalmente, a reflexão e as formas de agir em situações que envolvam qualquer tipo de agressão ou violência.

\section{REFERÊNCIAS}

BAKHTIN, Mikhail. Estética da criação verbal. Tradução: Maria Ermantina Galvão Gomes. Pereira. 3.ed. São Paulo: Martins Fontes, 2000.

BRASIL. Secretaria de Educação Fundamental. Parâmetros curriculares nacionais: terceiro e quarto ciclos do ensino fundamental: língua portuguesa/ Secretaria de Educação Fundamental. Brasília: MEC/SEF, 1998. Disponível em: http://basenacionalcomum.mec.gov.br/images/pcn/portugues.pdf. Acesso em: 18 jan. 2021.

BRASIL. Ministério da Educação. Base Nacional Comum Curricular: educação é a base. Brasília: MEC, 2017. Disponível em: http://basenacionalcomum.mec.gov.br/images/BNCC_20dez_site.pdf. Acesso em: 02 set. 2019. 
BRASIL. Ministério da Educação. Documento de Referência Curricular para Mato Grosso: ensino fundamental: anos iniciais. Cuiabá: [s. n.], 2018. Disponível em: https://drive.google.com/file/d/1pSppruO-tS9-puiU-IL01llcavKCJye5/view. Acesso em: 5 jun. 2020.

BRASIL. Ministério da Educação. Conselho Nacional de Educação. Parecer CNE/CP no 5/2020. Brasília: Ministério da Educação, 28 abr. 2020. Disponível em: http://portal.mec.gov.br/index.php?option=com_docman\&view=download\&alias=14511 pcp005-20\&category_slud=marco-2020-pdf\&Itemid=30192. Acesso em: 22 jun. 2021.

BRASIL. Ministério da Educação. Portaria nº 343, de 17 de março de 2020a. Dispõe sobre a substituição das aulas presenciais por aulas em meios digitais enquanto durar a situação de pandemia do Novo Coronavírus - COVID-19. Diário Oficial da União: seção 1, Brasília, DF, ano 158, n. 53, p. 39, 18 mar. 2020. Disponível em: http://www.in.gov.br/en/web/dou//portaria-n-343-de-17-de-marco-de-2020-248564376. Acesso em: 22 abr. 2020.

BRASIL. Ministério da Educação. Portaria n ${ }^{\circ} 345$, de 19 de março de 2020b. Altera a Portaria MEC $n^{\circ}$ 343, de 17 de março de 2020. Diário Oficial da União: seção 1, Brasília, DF, ano 158, n. 54-D, p. 1, 19 mar. 2020. Disponível em: http://www.in.gov.br/en/web/dou/-/portarian-345-de-19-de-marco-de-2020-248881422. Acesso em: 22 abr. 2020.

BRASIL. Ministério da Educação. Portaria n. ${ }^{\circ}$ 395, de 15 de abril de 2020c. Prorroga o prazo previsto no $\S 1^{\circ}$ do art. $1^{\circ}$ da Portaria $n^{\circ} 343$, de 17 de março de 2020. Diário Oficial da União: seção 1, Brasília, DF, ano 158, n. 73, p. 61, 16 abr. 2020. Disponível em: https://www.in.gov.br/web/dou/-/portaria-n-395-de-15-de-abril-de-2020-252725131. Acesso em: 22 abr. 2020.

CIEB. Planejamento das secretarias de educação do Brasil para ensino remoto. São Paulo, 2020. Disponível em: https://cieb.net.br/cieb-lanca-estrategias-de-aprendizagemremota-para-secretarias-de-educacao. Acesso em 11 jun. 2020.

COLASANTI, Marina., Para que ninguém a quisesse, Porém igualmente. In: COLASANTI, Marina. Um espinho de Marfim e outras histórias. Porto Alegre: L\&PM, 1999.

DOLZ, Joaquim.; NOVERRAZ, Michele.; SCHNEUWLY, Bernard. Sequências didáticas para o oral e a escrita: apresentação de um procedimento. IN: SCHNEUWLY, Bernard; DOLZ, Joaquim. Gêneros Orais e escritos na escola. Trad. e org. ROJO, Roxane.; CORDEIRO, Glais. Sales. São Paulo: Mercado das Letras, 2004.

FBSP. Violência doméstica durante a pandemia de Covid-19-Ed.2. São Paulo: Fórum Brasileiro de Segurança Pública [Internet]. São Paulo: FBPS; [2020]. Disponível em: http://forumseguranca.org.br/wp-content/uploads/2020/06/violencia-domestica-covid-19ed02-v5.pdf. Acesso em 03 set. 2020.

FORNARI, Lucimara Fabiana et al. Violência doméstica contra a mulher na pandemia: estratégias de enfrentamento divulgadas pelas mídias digitais. Revista Brasileira de Enfermagem, v. 74, suppl 1, 2021. https://doi.org/10.1590/0034-7167-2020-0631 
GALINDO, Daniel. Comunicação mercadológica: uma revisão conceitual. In: GALINDO, Daniel (org.). Comunicação institucional e mercadológica: expansões conceituais e imbricações temáticas. São Bernardo do Campo: Universidade Metodista, 2012.

LAJOLO, Marisa. O texto não é pretexto. In: ZILBERMAN, Regina.(org.) Leitura em crise na escola: as alternativas do professor. Porto Alegre, Mercado Aberto, 1986.

MINISTÉRIO DA SAÚDE. Sobre a doença. In: BRASIL. Ministério da Saúde. Coronavírus (COVID-19). Brasília: Ministério da Saúde, [2020]. Disponível em:

https://coronavirus.saude.gov.br/sobre-a-doenca\#o-que-e-covid. Acesso em: 23 jun. 2020.

SANTOS, Edméia. EAD, palavra proibida. Educação online, pouca gente sabe o que é. Ensino remoto, o que temos para hoje. Mas qual é mesmo a diferença? Revista Docência e Cibercultura, Rio de Janeiro, ago. 2020. Seção Notícias. ISSN 2594-9004. Disponível em: https://www.e-publicacoes.uerj.br/index.php/re-doc/announcement/view/1119. Acesso em: 25 jun. 2020.

TORRES, Maximiliano. A desconstrução do feminino em Grimm e Marina Colasanti. UFRJ, Rio de Janeiro, 2008.

VALENTE, José Armando. Formação de Profissionais na Área de Informática em Educação, In VALENTE, José. Armando. (org.). Computadores e Conhecimento: Repensando a Educação. Campinas: Gráfica Central da Unicamp, 1995.

ZALUAR, Alba. Violência, crime organizado e poder: a tragédia brasileira e seus desafios. In: VELLOSO, João Paulo. (org.). Governabilidade, sistema político e violência urbana. Rio de Janeiro, José Olympio, 1994. 